\title{
Wind Velocity Profile and Representative Wind Velocity for Wind Resistance Measurement of Ship Models
}

\author{
by Kenichi Kume*, Member \\ Hideo Orihara**, Member
}

\author{
Hiroki Ohba ${ }^{*}$, Member \\ Shuji Mizokami***, Member
}

\begin{abstract}
Summary
Wind resistances and moment acting on a ship model measured in a wind tunnel are non-dimensionalized using the air density, the projected area of the model and the representative wind velocity. However, there is no common definition of the representative wind velocity in wind tunnel tests for ships, thus wind velocities which are obtained by an anemometer fixed in a certain place in a wind tunnel or measured at a height equivalent to $10 \mathrm{~m}$ from the sea surface are often used. In principle, there is no problem as long as the wind velocity profile under the same condition is assumed and the wind velocity at the same position is employed when the wind resistance coefficients are converted into forces of different scales. Nevertheless, if the wind velocity distributions between in the wind tunnel test and the assumed distribution by the user are different, the wind resistance coefficients cannot be used in the first place. And the existence of various definitions of non-dimensionalization makes it difficult to simply compare wind resistance coefficients themselves.

Since it is meaningful to clarify the definition of the representative wind velocity which can provide wind resistances in a realistic and reasonable manner using the wind resistance coefficients without being influenced by the assumed wind velocity distribution, it was derived from the results of wind tunnel tests under the conditions of various wind velocity profiles and using various types of ship models. Furthermore, the influence of the wind velocity profile on the wind resistance measurement was evaluated with the results of the wind resistance measurement in different wind velocity profiles. Several findings on the wind velocity profile required for wind resistance measurements are reported in this paper.
\end{abstract}

\section{Introduction}

A wind tunnel test is one of the methods for accurately obtaining the wind resistance acting on a ship. In a wind tunnel test, a ship model is placed in a tunnel and the measurement is made for the hydrodynamic forces acting on it. Since the model test is generally performed to predict the hydrodynamic forces acting on the ship, the measured wind resistance is nondimensionalized using the air density, the projected area of the model and the representative wind velocity. However there is no common definition of the representative wind velocity in the wind tunnel test. Thus, wind velocities which are obtained by an anemometer fixed in a certain place in a wind tunnel or measured at a height equivalent to $10 \mathrm{~m}$ from the sea surface are often used. Nevertheless, if the wind velocity distributions between in the wind tunnel test and the assumed distribution by the user are different, the wind resistance coefficients cannot be used in the first place. As long as the wind resistance coefficients are converted into the wind resistances with the wind velocity at the same position of the same profile, contradiction does not occur. But it may be difficult to implement in the aspect of time and cost.

\footnotetext{
* National Maritime Research Institute, MPAT

** Japan Marine United Corporation

*** Mitsubishi Shipbuilding Co., Ltd.
}

There is also a demerit that it makes hard to simply compare wind resistance coefficients themselves non-dimensionalized by representative wind velocities of different definitions.

Since it is meaningful to clarify the definition of the representative wind velocity which can provide wind resistances in a realistic and reasonable manner using the wind resistance coefficients without being influenced by the assumed wind velocity distribution, it was derived from the results of wind tunnel test under the conditions of various wind velocity profiles and using multiple types of ship models.

In addition, from the results of wind resistance measurements in different wind velocity profiles, the influence of the difference of the profiles has been evaluated and the wind velocity profile to be used for wind resistance measurement has been investigated.

In this paper, the appropriate method for the representative wind velocity determination is derived from the results of wind resistance measurements. And it also concluded that there is a certain degree of freedom in the wind velocity profile to be used during wind tunnel tests.

\section{Dimensions of Wind Tunnel and Ship Models}

Wind resistance measurements were carried out in the wind tunnel of National Maritime Research Institute (NMRI). The plan view of the tunnel is illustrated in Fig. 1. In order to ensure the effectiveness of the study, as many different types of ships as possible were selected as test models, which are the models of Bulk Carrier, Chemical Tanker, Container Ship (Full Load and 
Ballast conditions) and Pure Car Carrier (PCC). The specifications of the wind tunnel and test models are shown in the following section.

\section{1 Wind Tunnel}

- Gettingen-type horizontal recirculation system

- Wind tunnel measuring part: Closed type, $3 \mathrm{~m}$ width, $2 \mathrm{~m}$ height and $15 \mathrm{~m}$ length

- Performance of fan: Steady wind velocity $1.0 \sim 30 \mathrm{~m} / \mathrm{s}$

- Turbulence intensity: less than $0.5 \%$

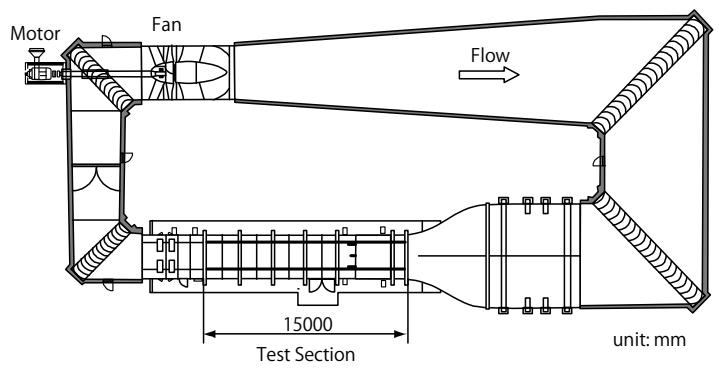

Fig. 1 Plan view of wind tunnel in NMRI.

\section{2 Ship Models}

Figs. $2 \sim 6$ show the views of front and side projection of the 5 conditions for 4 models. The principal dimensions are shown in Table 1, where $L_{O A}$ is length overall, $L_{P P}$ is length between perpendiculars, $B$ is Breadth and $d_{m}$ is mean draft. The $L_{P P}$ of the model ships was all set to $1.2 \mathrm{~m}$.

Table 1 Dimensions of subject ships in ship scale.

\begin{tabular}{|c|c|c|c|c|c|c|}
\hline $\begin{array}{l}\text { Type of } \\
\text { ships }\end{array}$ & Condition & $\begin{array}{l}L_{O A} \\
{[\mathrm{~m}]} \\
\end{array}$ & $\begin{array}{l}L_{P P} \\
{[\mathrm{~m}]}\end{array}$ & $\begin{array}{c}B \\
{[\mathrm{~m}]}\end{array}$ & $\begin{array}{c}d_{m} \\
{[\mathrm{~m}]}\end{array}$ & $\begin{array}{c}\text { Trim } \\
{[\mathrm{m}]}\end{array}$ \\
\hline $\begin{array}{c}\text { Bulk } \\
\text { Carrier }\end{array}$ & Full Load & 291.3 & 280.0 & 45.0 & 16.5 & 0.0 \\
\hline $\begin{array}{c}\text { Chemical } \\
\text { Tanker }\end{array}$ & Full Load & 177.6 & 170.5 & 27.7 & 10.0 & 0.0 \\
\hline \multirow{2}{*}{$\begin{array}{c}\text { Container } \\
\text { Ship }\end{array}$} & Full Load & \multirow{2}{*}{311.7} & \multirow{2}{*}{300.0} & \multirow{2}{*}{40.0} & 14.0 & 0.0 \\
\hline & Ballast & & & & 11.2 & 0.0 \\
\hline PCC & Full Load & 200.0 & 190.0 & 32.26 & 7.6 & 0.0 \\
\hline
\end{tabular}
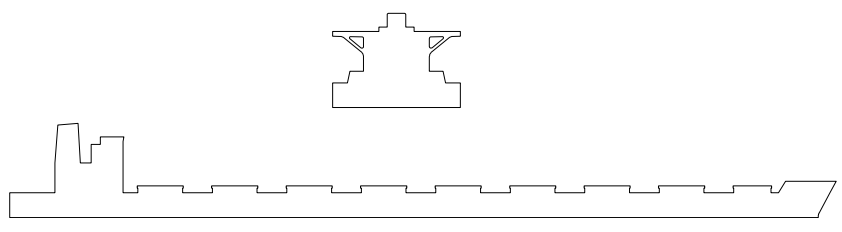

Fig. 2 Projected shape of Bulk Carrier.

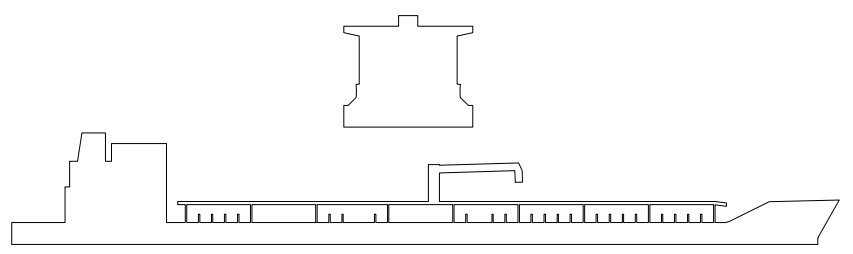

Fig. 3 Projected shape of Chemical Tanker.

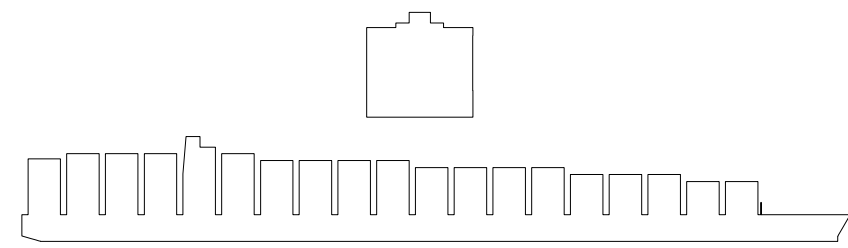

Fig. 4 Projected shape of Container Ship (Full Load Condition).

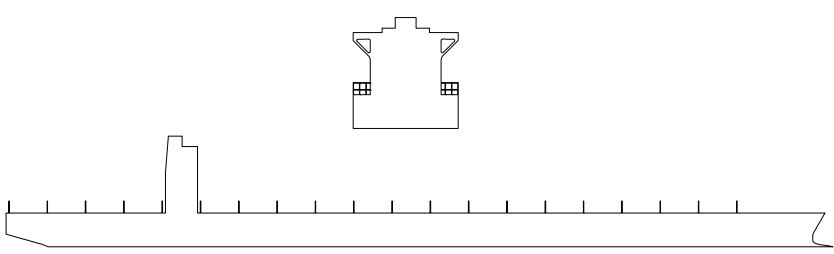

Fig. 5 Projected shape of Container Ship (Ballast Condition).

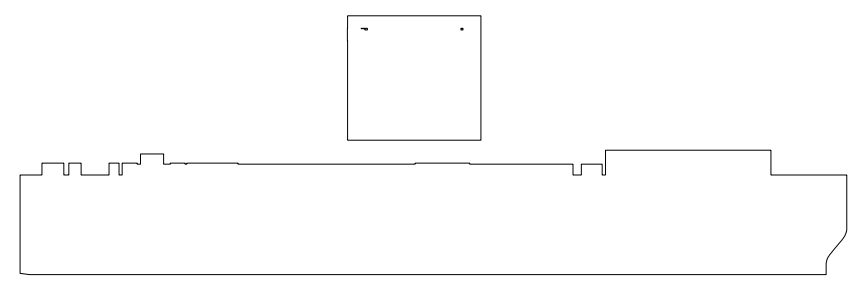

Fig. 6 Projected shape of PCC.

\section{3 Blockage Ratio}

The blockage ratio is one of the main parameters to be considered in order to accurately measure the wind resistance in the wind tunnel. The blockage ratio means the proportion of the area occupied by the model to the cross-sectional area of the wind tunnel. In the range of $5 \%$ or less, the influence of the blockage ratio is small and it is reported to be acceptable ${ }^{1)}$. Table 2 shows the blockage ratio when the ship models shown in the previous section are installed in the wind tunnel of NMRI (Cross-sectional dimensions of the measurement section: $3 \times 2 \mathrm{~m}$ ). In all the cases, the blockage ratios are less than $5 \%$ at the wind direction angle $\psi$ (cf. Fig. 14) of 90 deg. at which the pressure receiving area of the model becomes the maximum. From Table 2, it is apparent there is less influence in the wind resistance test.

Table 2 Blockage ratio (Beam wind, $\psi=90 \mathrm{deg}$.).

\begin{tabular}{|c|c|c|}
\hline Type of ships & Condition & Blockage ratio \% \\
\hline Bulk Carrier & Full Load & 1.0 \\
\hline Chemical Tanker & Full Load & 1.2 \\
\hline \multirow{2}{*}{ Container Ship } & Full Load & 2.0 \\
\cline { 2 - 3 } & Ballast & 1.2 \\
\hline PCC & Full Load & 3.6 \\
\hline
\end{tabular}

\section{Wind Velocity Profile and Turbulence Distribution in the Wind Tunnel}

In the measurement of the wind resistance test, the model ship is placed on a turntable to change the wind direction. The midship position of the center line of the model ship is fixed to the center position of the turntable. In order to vary the boundary layer 
thickness in the wind resistance tests, the installation position of the model ship in the wind tunnel is to be changed as well as the turntable is to be lifted from the floor of the wind tunnel to make the boundary layer thinner as shown in Fig. 7. The positions are named Case-A, -B and -C. Wind velocity profiles are measured by a 5 -hole pitot tube shown in Fig. 8 . The 5-hole pitot tube which has a diameter of $3 \mathrm{~mm}$ was chosen so as not to distort the measured flow. Figs. 9(a) 9(c) and Figs. 10(a) 10(c) show the wind velocity profiles and the intensity distributions of turbulence at the center of the turntable at each position without a model. The projected shapes of the front view in the figures are the shape of Bulk Carrier for reference. The pressure sampling frequency was set to $200 \mathrm{~Hz}$ in order to measure the intensity of the turbulence. The response characteristics of the flow velocity measurement system consisting of a 5-hole pitot tube and pressure gauges are $20 \mathrm{~Hz}$ or less.

In the wind velocity profiles of Case-A and Case-B shown in Fig. 9(a) and Fig. 9(b), a thick boundary layer developed on the wind tunnel floor surface is seen, and the each thickness $\delta$ is approximately $130 \mathrm{~mm}$ and $90 \mathrm{~mm}$ respectively. In addition, the figures show that the shapes of the boundary layer distribution have the equivalent properties with the $1 / 7$ power distribution represented by the Eq. (1) as $\alpha=1 / 7$. On the other hand, the wind velocity profile of Case-C shown in Fig. 9(c) is the case where the boundary layer is thinner than the others. A separated floor to lift the model up from the boundary layer is installed in the wind tunnel. The thickness $\delta$ of the boundary layer of Case-C is approximately $30 \mathrm{~mm}$. However, the vertical distribution of the wind velocity in Case- $\mathrm{C}$ was not uniform in the lateral direction of the wind tunnel, so the data of wind resistance in the Case- $\mathrm{C}$ is adopted only in the range of $\psi=0$ to 30 and 150 to $180 \mathrm{deg}$. which can be analyzed using only the wind velocity profile in the center of the turntable.

Figs. 10(a) $\sim 10$ (c) show the intensity of the turbulence of the wind velocity calculated by Eq. (2) and those are considerably smaller than the figures observed in the ocean wind.

$$
\begin{gathered}
U(z)=\left(z / z_{10 m}\right)^{\alpha} \cdot U_{10 m} \\
I_{U}(z)=\sigma_{U}(z) / U(z)
\end{gathered}
$$

Where, $U(z)$ is the wind velocity at each height, $I_{U}(z)$ is the turbulence intensity and $\sigma_{U}(z)$ is the standard deviation of the velocity at each height, $z$ is the vertical distance from the sea surface, $z_{10 m}$ is the reference height of $10 \mathrm{~m}$ in ship scale, $U_{10 \mathrm{~m}}$ is the average wind velocity at the reference height, and $\alpha$ is the power index of the power law $(1 / 9 \sim 1 / 7$ in the case of ocean wind).

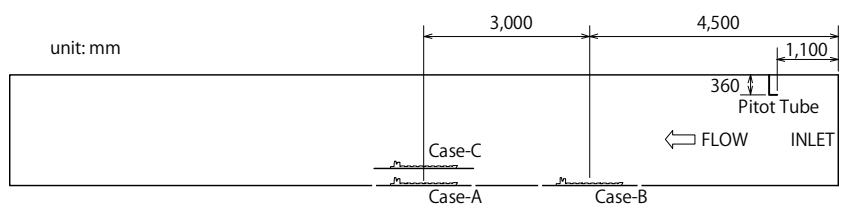

Fig. 7 Measurement positions in the longitudinal direction of the wind tunnel.

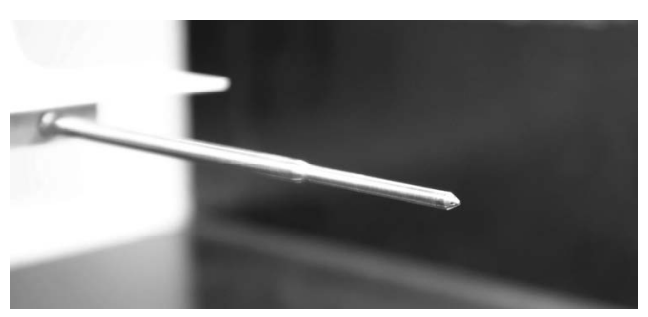

Fig. 8 5-hole pitot tube.

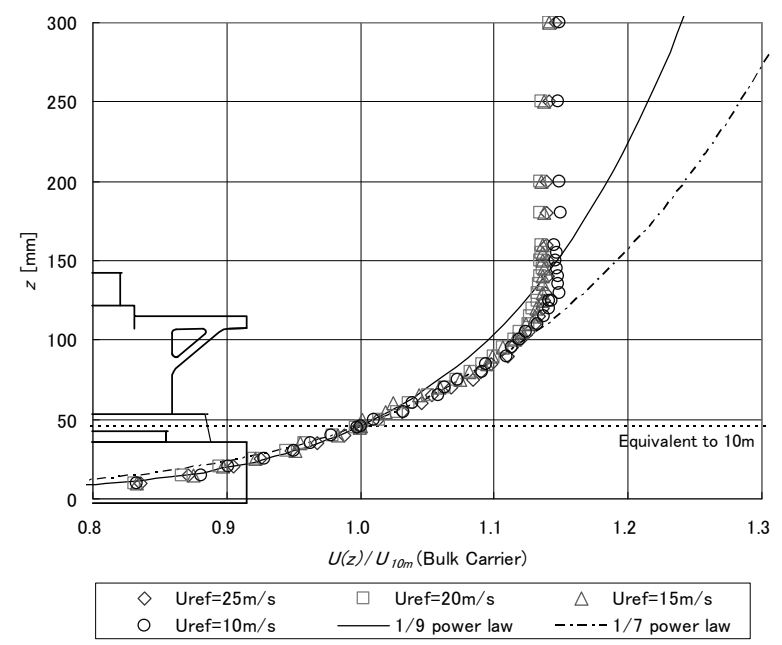

Fig. 9(a) Wind velocity profile at the centerline of the midship (Case-A) $(\delta=$ abt. $130 \mathrm{~mm})$.

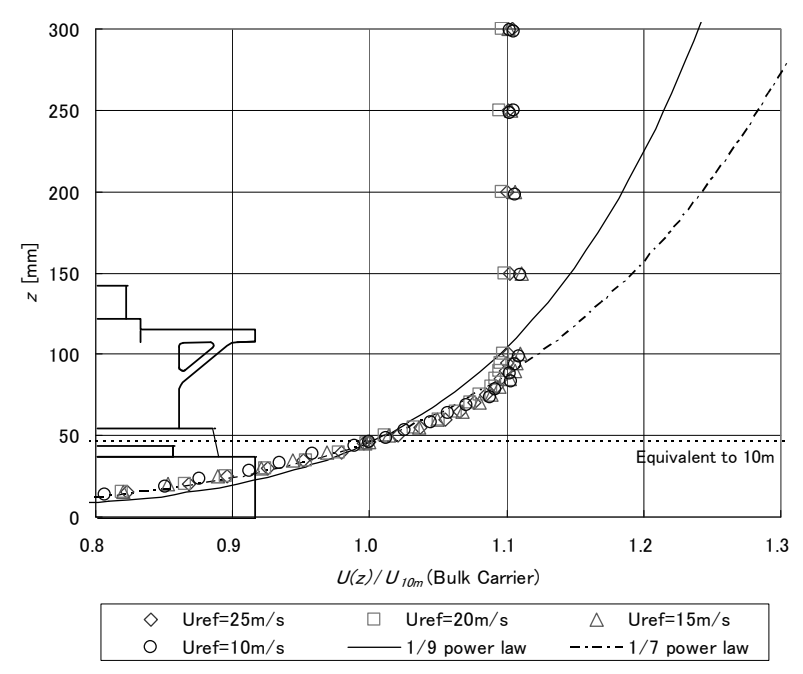

Fig. 9(b) Wind velocity profile at the centerline of the midship (Case-B) $(\delta=$ abt. $90 \mathrm{~mm})$. 


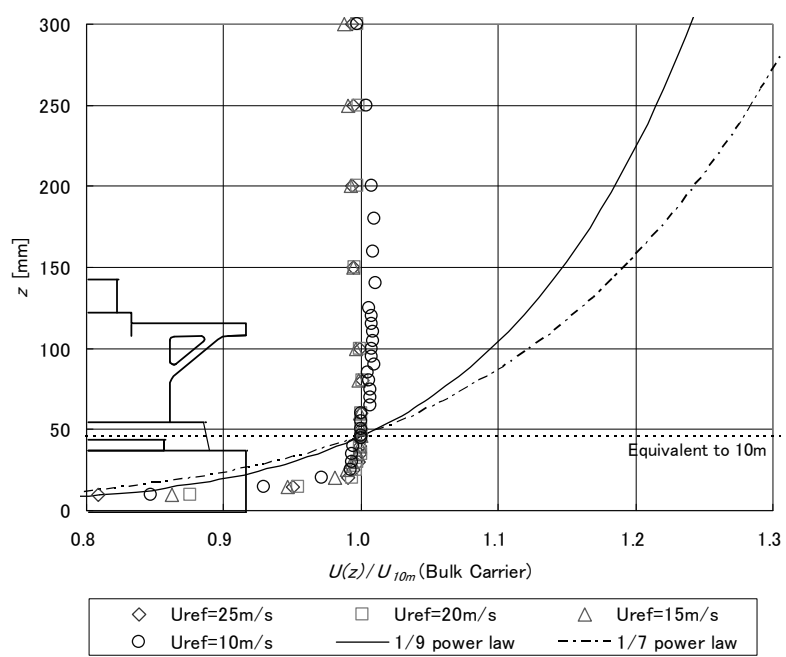

Fig. 9(c) Wind velocity profile at the centerline of the midship (Case-C) $(\delta=$ abt. $30 \mathrm{~mm})$.

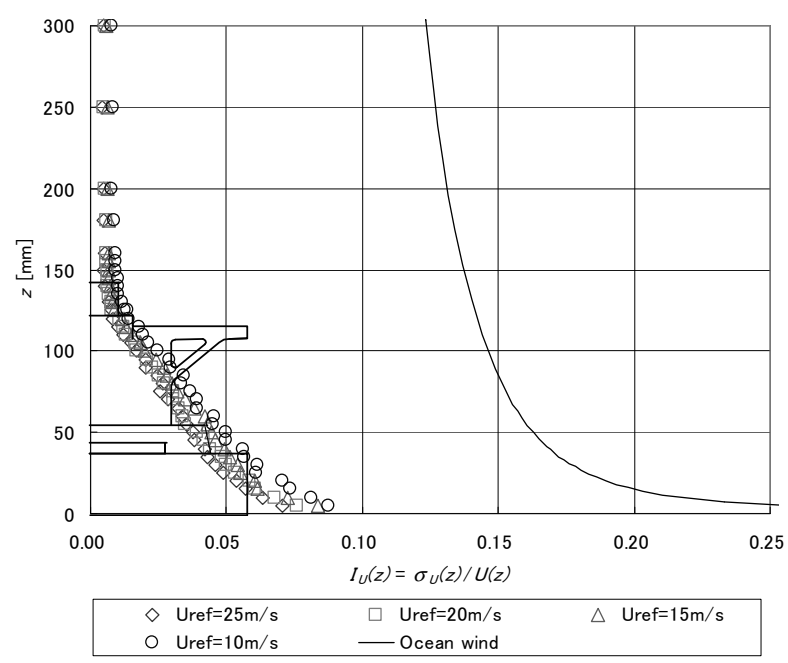

Fig. 10(a) Distribution of the turbulence intensity at the centerline of the midship (Case-A) $(\delta=$ abt. $130 \mathrm{~mm})$.

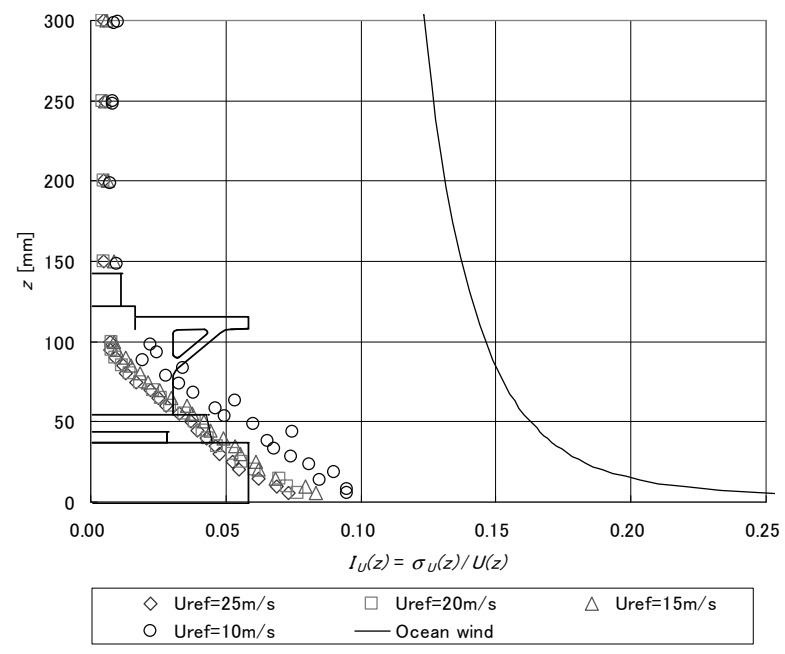

Fig. 10(b) Distribution of the turbulence intensity at the centerline of the midship (Case-B) ( $\delta=$ abt. $90 \mathrm{~mm}$ ).

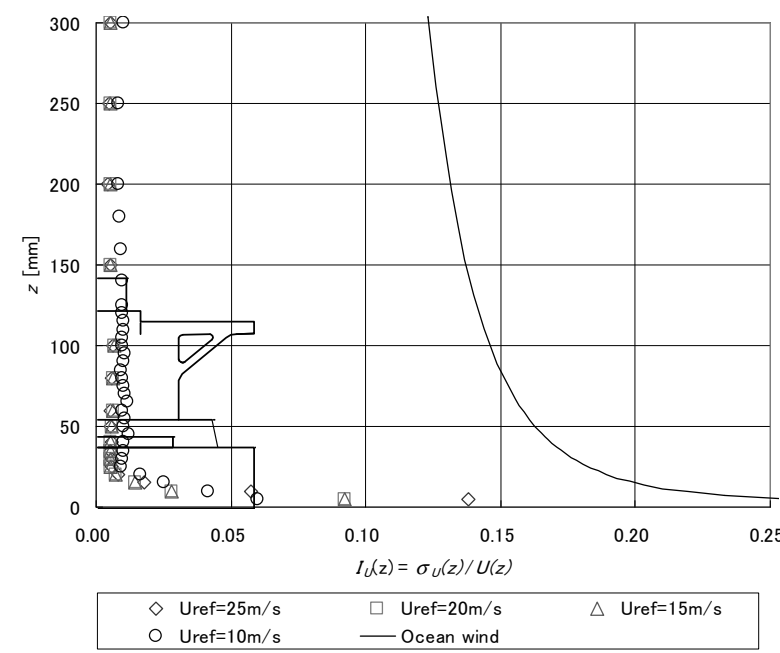

Fig. 10(c) Distribution of the turbulence intensity at the centerline of the midship (Case-C) $(\delta=$ abt. $30 \mathrm{~mm})$.

\section{Representative Height and Wind Velocity}

\section{1 Representative Height}

Here, calculation method of representative wind velocity used for non-dimensionalization which includes the integration of wind velocity is investigated with reference to the concept of dynamic pressure which the effectiveness has been shown in the references 3) and 4). The method is adopted so that it can be applicable to a flow having a thick boundary layer developed on the wind tunnel floor or an arbitrary flow distribution such as a power law distribution, with reference to the documents ${ }^{2)-5}$. The averaged wind velocities $U_{A 1}$ and $U_{A 2}$ shown in Fig. 11, which are used for non-dimensionalizing the longitudinal force $F_{X}$, the lateral force $F_{Y}$ and yaw moment $C_{N}$ shown in Fig. 13 are obtained by dividing the rectangle area drawn with a dashed line in Fig. 11 by representative heights $H_{B R}$ or $H_{L}$. The equations are as follows.

$$
\begin{aligned}
& U_{A 1}{ }^{2}=A_{1} / H_{B R} \\
& U_{A 2}{ }^{2}=A_{2} / H_{L}
\end{aligned}
$$

Where, $A_{1}$ and $A_{2}$ is the rectangular area equivalent to the area calculated from an integral of the wind velocity profile in the range from the bottom of the model to the height of $H_{B R}$ or $H_{L}$ respectively. $H_{B R}$ is the height of the top of the navigation bridge from the sea surface and $H_{L}$ is the average height which is derived from dividing the side projected area $A_{L}$ of a ship by the ship length $\left(L_{O A}\right)$ as shown in the Fig. 12(a) and Fig. 12(b).

Table 3 Representative heights of the ships in model scale.

\begin{tabular}{|c|c|c|c|c|}
\hline Type of ships & Condition & $\begin{array}{c}z_{10 m} \\
{[\mathrm{~mm}]}\end{array}$ & $\begin{array}{c}H_{B R} \\
{[\mathrm{~mm}]}\end{array}$ & $\begin{array}{c}H_{L} \\
{[\mathrm{~mm}]}\end{array}$ \\
\hline Bulk Carrier & Full Load & 42.9 & 121.8 & 49.6 \\
\hline Chemical Tanker & Full Load & 70.4 & 152.0 & 56.6 \\
\hline \multirow{2}{*}{ Container Ship } & Full Load & \multirow{2}{*}{40.0} & 141.3 & 96.1 \\
\cline { 2 - 2 } \cline { 5 - 5 } & Ballast & & 152.5 & 54.7 \\
\hline PCC & Full Load & 63.2 & 189.5 & 169.2 \\
\hline
\end{tabular}


In references 2) to 5), the dynamic pressure at $H_{L}$, the average dynamic pressure up to $H_{L}$ and the experimental constant are combined and used for non-dimensionalization of wind resistances, whereas this paper suggests a simpler method and confirms the effectiveness. Table 3 summarizes the $H_{B R}$ and $H_{L}$ for each ship type.

\section{2 Wind Velocity}

The wind resistance measurement was performed at four wind velocities in order to investigate the Reynolds number effect. The wind velocities during the test were set to be 10,15, 20, and 25 $\mathrm{m} / \mathrm{s}$ so that the reference wind velocity $U_{\text {ref }}$ measured by a pitot tube. As shown in Fig. 7 and Fig. 13, the pitot tube was installed at the top of the measurement chamber, approximately $3,400 \mathrm{~mm}$ upstream from the center of the turntable in Case-B and $360 \mathrm{~mm}$ down from the ceiling surface. Tables $4 \sim 6$ summarize the averaged wind velocities, $U_{A 1}$ and $U_{A 2}$, and the wind velocity at the height equivalent to $10 \mathrm{~m}$ in a ship scale, $U_{10 \mathrm{~m}}$, for each set. When calculating $U_{A 1}, U_{A 2}$ and $U_{10 m}$, trapezoidal integration and interpolation were performed on the data measured in the wind tunnel.

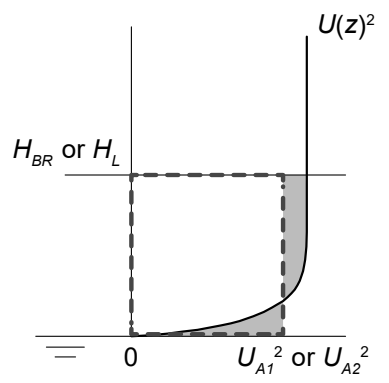

Fig. 11 Conceptual figure of averaged wind velocities $U_{A I}$ and $U_{A 2}$ analyzed with integration.

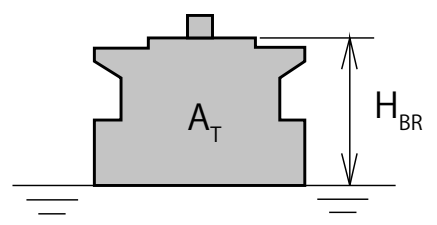

Fig. 12(a) Conceptual figure of $H_{B R}$.

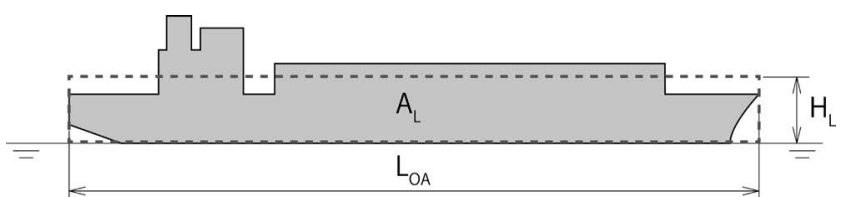

Fig. 12(b) Conceptual figure of $H_{L}$.

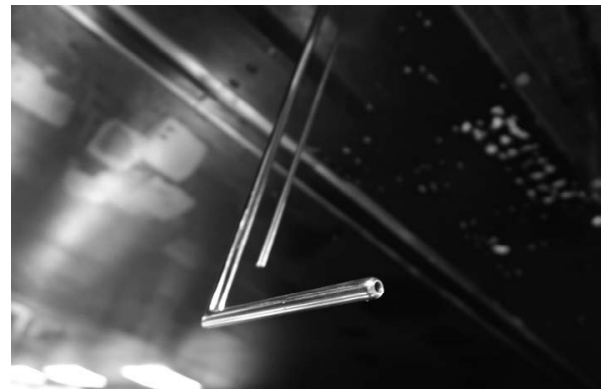

Fig. 13 Pitot tube in the wind tunnel.
Table 4 Averaged wind velocity $U_{A l}$ for $F_{X}$

\begin{tabular}{|c|c|c|c|c|c|}
\hline for $F_{X}$ & & \multicolumn{4}{|c|}{$U_{\text {ref }}[\mathrm{m} / \mathrm{s}]$} \\
\hline \multirow{4}{*}{ Bulk Carrier } & & 10.00 & 15.00 & 20.00 & 25.00 \\
\cline { 2 - 6 } & Case & \multicolumn{4}{|c|}{$U_{A I}[\mathrm{~m} / \mathrm{s}]$} \\
\hline & $\mathrm{A}$ & 9.187 & 13.86 & 18.40 & 22.98 \\
\cline { 2 - 6 } & $\mathrm{B}$ & 9.371 & 13.97 & 18.60 & 23.19 \\
\cline { 2 - 6 } & $\mathrm{C}$ & 10.13 & 15.25 & 20.15 & 25.10 \\
\hline \multirow{2}{*}{$\begin{array}{c}\text { Chemical Tanker } \\
\text { Container Ship } \\
\text { (Full Load) }\end{array}$} & $\mathrm{A}$ & 9.440 & 14.18 & 18.91 & 23.79 \\
\cline { 2 - 6 } & $\mathrm{C}$ & 10.18 & 15.30 & 20.21 & 25.20 \\
\hline \multirow{2}{*}{$\begin{array}{c}\text { Container Ship } \\
\text { (Ballast) }\end{array}$} & $\mathrm{A}$ & 9.367 & 14.10 & 18.81 & 23.66 \\
\cline { 2 - 6 } & $\mathrm{A}$ & 10.16 & 15.29 & 20.19 & 25.17 \\
\hline \multirow{2}{*}{ PcC } & $\mathrm{C}$ & 10.13 & 15.30 & 20.21 & 25.20 \\
\cline { 2 - 6 } & $\mathrm{A}$ & 9.619 & 14.43 & 19.23 & 24.19 \\
\hline \multirow{2}{*}{ C } & 10.22 & 15.33 & 20.26 & 25.27 \\
\hline
\end{tabular}

Table 5 Averaged wind velocity $U_{A 2}$ for $F_{Y}$ and $M_{Z}$.

\begin{tabular}{|c|c|c|c|c|c|}
\hline for $F_{Y}, M_{Z}$ & & \multicolumn{4}{|c|}{$U_{\text {ref }}[\mathrm{m} / \mathrm{s}]$} \\
\hline \multirow{4}{*}{ Bulk Carrier } & & 10.00 & 15.00 & 20.00 & 25.00 \\
\cline { 2 - 6 } & Case & \multicolumn{4}{|c|}{$U_{A 2}[\mathrm{~m} / \mathrm{s}]$} \\
\hline & $\mathrm{A}$ & 8.256 & 12.47 & 16.54 & 20.64 \\
\cline { 2 - 6 } & $\mathrm{B}$ & 8.261 & 12.30 & 16.52 & 20.59 \\
\cline { 2 - 6 } & $\mathrm{C}$ & 9.782 & 14.85 & 19.61 & 24.20 \\
\hline \multirow{2}{*}{\begin{tabular}{c} 
Chemical Tanker \\
\cline { 2 - 6 }
\end{tabular}} & $\mathrm{A}$ & 8.329 & 12.55 & 16.88 & 21.23 \\
\cline { 2 - 6 } $\begin{array}{c}\text { Container Ship } \\
\text { (Full Load) }\end{array}$ & $\mathrm{C}$ & 9.846 & 14.94 & 19.72 & 24.39 \\
\hline \multirow{2}{*}{$\begin{array}{c}\text { Container Ship } \\
\text { (Ballast) }\end{array}$} & $\mathrm{C}$ & 8.928 & 13.47 & 18.02 & 22.67 \\
\cline { 2 - 6 } & $\mathrm{A}$ & 8.307 & 12.54 & 16.87 & 21.21 \\
\hline \multirow{2}{*}{ PCC } & $\mathrm{C}$ & 9.830 & 14.92 & 19.69 & 24.34 \\
\cline { 2 - 6 } & $\mathrm{A}$ & 9.535 & 14.32 & 19.08 & 24.00 \\
\hline \multirow{4}{*}{ C } & 10.20 & 15.32 & 20.24 & 25.23 \\
\hline
\end{tabular}

Table 6 Wind velocity $U_{10 m}$ at the height of $10 \mathrm{~m}$ in ship scale.

\begin{tabular}{|c|c|c|c|c|c|}
\hline & & \multicolumn{4}{|c|}{$U_{\text {ref }}[\mathrm{m} / \mathrm{s}]$} \\
\hline & & 10.00 & 15.00 & 20.00 & 25.00 \\
\cline { 2 - 6 } & Case & \multicolumn{4}{|c|}{$U_{10 \mathrm{~m}}[\mathrm{~m} / \mathrm{s}]$} \\
\hline \multirow{3}{*}{ Bulk Carrier } & A & 8.925 & 13.53 & 17.96 & 22.29 \\
\cline { 2 - 6 } & $\mathrm{B}$ & 9.234 & 13.74 & 18.39 & 22.78 \\
\cline { 2 - 6 } & $\mathrm{C}$ & 10.29 & 15.57 & 20.53 & 25.71 \\
\hline \multirow{2}{*}{ Chemical Tanker } & $\mathrm{A}$ & 9.563 & 14.39 & 19.17 & 24.13 \\
\cline { 2 - 6 } & $\mathrm{C}$ & 10.36 & 15.54 & 20.55 & 25.73 \\
\hline \multirow{2}{*}{ Container Ship } & $\mathrm{A}$ & 8.805 & 13.29 & 17.81 & 22.39 \\
\cline { 2 - 6 } (Full Load, Ballast) & $\mathrm{C}$ & 10.27 & 15.56 & 20.53 & 25.70 \\
\hline \multirow{2}{*}{ PCC } & $\mathrm{A}$ & 9.417 & 14.18 & 18.91 & 23.80 \\
\cline { 2 - 6 } & $\mathrm{C}$ & 10.35 & 15.56 & 20.54 & 25.73 \\
\hline
\end{tabular}

\section{Measurement Results of Wind Resistance}

\section{1 Coordinate System and Non-dimensionalization of Wind}

\section{Resistances}

Wind resistances act on the model ships were measured with a load cell fixed to the midship which is the rotation center of the hull. Since the hull and the load cell are fixed to each other, the direction of the hydrodynamic forces $F_{X}$ and $F_{Y}$ always coincide with the axes of the hull as shown in Fig. 14. The sampling frequency of wind resistance is $100 \mathrm{~Hz}$, low-pass filter is not used. The wind resistances and moment are non-dimensionalized by the Eqs. (5) (7). 


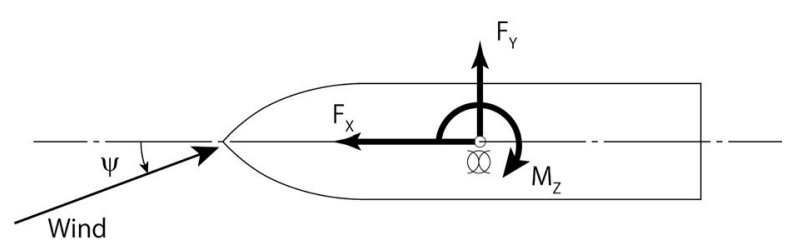

Fig. 14 Coordinate system.

$$
\begin{gathered}
C_{X}=F_{X} /\left(\frac{1}{2} \rho U^{2} A_{T}\right) \\
C_{Y}=F_{Y} /\left(\frac{1}{2} \rho U^{2} A_{L}\right) \\
C_{N}=M_{Z} /\left(\frac{1}{2} \rho U^{2} A_{L} \cdot L_{O A}\right)
\end{gathered}
$$

Where, $\rho$ is the air density, $U$ is the representative wind velocity, $A_{T}$ and $A_{L}$ are the projected areas of transverse and longitudinal sections and $L_{O A}$ is length over all, respectively.

\section{2 Effect of Reynolds Number}

The Reynolds number $R_{e}$ at the wind tunnel test is shown in Table 7. $U_{r e f}$ is used for the Reynolds number calculation. According to the references ${ }^{4) 677)}$, if $R_{e}$ becomes $1.0 \times 10^{6}$ or more, the influence of the Reynolds number on the wind resistance is negligible. Fig. 15 shows the changes in $C_{X}, C_{Y}$ and $C_{N}$ according to the Reynolds number in this study. As for the wind tunnel tests using the models with the length of $1.2 \mathrm{~m}$, the negligible condition can be applied when $R_{e}$ is $1.2 \times 10^{6}\left(U_{\text {ref }}\right.$ is $\left.15 \mathrm{~m} / \mathrm{s}\right)$ or more.

Table 7 Reference velocity $U_{\text {ref }}$ at the upstream end of wind tunnel and Reynolds numbers.

\begin{tabular}{|c|c|}
\hline$U_{\text {ref }}[\mathrm{m} / \mathrm{s}]$ & $R_{e}\left[\times 10^{6}\right]$ \\
\hline 10.00 & 0.81 \\
\hline 15.00 & 1.21 \\
\hline 20.00 & 1.62 \\
\hline 25.00 & 2.02 \\
\hline
\end{tabular}

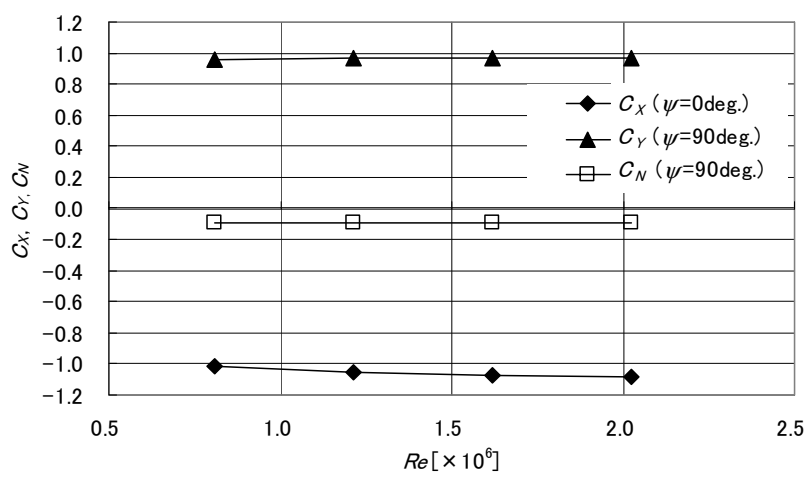

Fig. 15 Changes in $C_{X}, C_{Y}$ and $C_{N}$ to Reynolds number (Chemical Tanker).

\section{3 Representative Wind Velocity and Wind Velocity Profile in Wind Tunnel Test}

The coefficients of $C_{X}, C_{Y}$ and $C_{N}$ measured in three different wind velocity profiles (Case-A $\sim$ Case-C) are shown in Figs. $16 \sim$ 30 for each representative wind velocity and ship type. Only the results of $U_{r e f}=25 \mathrm{~m} / \mathrm{s}$ are shown in those diagrams because there are no Reynolds number effect in the velocity as indicated in Fig. 15. In the case of $U_{r e f}$ is used for non-dimensionalization of wind resistance and moment in any type of ships, the data of $C_{X}, C_{Y}$ and $C_{N}$ are varied due to the difference in wind velocity profiles, while it is found that the agreements of $C_{X}, C_{Y}$ and $C_{N}$ are improved when the averaged wind velocities $U_{A 1}, U_{A 2}$ or the wind velocity $U_{10 m}$ are used. Fig. 31 shows the coefficient of variation of $C_{X}$ of Bulk Carrier as an example. At wind direction angles ( $\psi$ $=0$ to 30,150 to $180 \mathrm{deg}$ ) where $C_{X}$ has a large effect, the maximum variation is about 0.17 in absolute value when $U_{\text {ref }}$ is used, while the coefficient of variation becomes small to 0.07 or less in absolute value when $U_{A l}$ or $U_{I 0 m}$ is used.

This is probably due to the fact that $U_{\text {ref }}$ does not properly represent the inflow velocity, because it is measured at a distant position from the model ship. On the other hand, the reason why the $C_{X}, C_{Y}$ and $C_{N}$ in different wind conditions are agreed with each other when using the averaged wind velocities $U_{A 1}$ and $U_{A 2}$ is that those were derived based on the concept of kinematic energy by integrating the square of the wind velocity and helps to perform an adequate calculation of wind resistance coefficients. In addition, when $U_{I 0 m}$ is used, $C_{X}, C_{Y}$ and $C_{N}$ also show good agreement. It is thought that most part of the wind velocity profile in the region of the model ships is similar to the profile of $1 / 7$ power law distribution for Case-A and Case-B, and uniform flow for Case-C. It inevitably gives a high correlation between $U_{10 \mathrm{~m}}$ and $U_{A 1}, U_{A 2}$ as shown in Fig. 32(a) and Fig. 32(b), and results in good agreement. However, it is still recommended to use the averaged wind velocities $U_{A l}$ and $U_{A 2}$, because when the wind velocity profile becomes more arbitrary, such as not following a power law, the correlation may be lowered even if it is nondimensionalized by $U_{10 m}$. $U_{10 m}$ is just one value measured at a fixed height where wind velocity profile cannot be taken into account. Furthermore, a significant difference appears in the absolute values of $C_{X}, C_{Y}$ and $C_{N}$ depending on whether $U_{A 1}, U_{A 2}$ or $U_{10 m}$ applies for non- dimensionalization, which is seen in Fig. 22(b) and Fig. 22(c) for example. From the investigation, it is considered preferable to use the averaged wind velocities $U_{A I}$ and $U_{A 2}$ including the kinematic energy concept, in order to reduce the influence of the difference of wind velocity profiles, which differ depending on the test facilities and model ship size.

Further, from another viewpoint of setting wind conditions in a wind tunnel, as long as the non-dimensionalization using the averaged wind velocities $U_{A 1}$ and $U_{A 2}$ is performed, the data of wind resistance coefficient show good agreement within the range of the above-mentioned variation regardless of wind velocity profile and thus the wind velocity profile during the wind resistance test is not necessary to be simulated the power law distribution or the advance speed of a ship which a ship will encounter at sea.

It can be found that a wind velocity profile having a characteristic of a uniform flow or a naturally developed boundary layer on the wind tunnel floor is appropriate to be used 
for the wind resistance measurement.

\section{4 Round Robin Tests with Bulk Carrier Model in Three Wind Tunnels}

In order to confirm the validity of the test results at NMRI, wind resistance measurements were carried out as round robin tests with the same ship model (Bulk Carrier model) in the other two wind tunnels in Japan. The photographs under the round robin tests are shown in Figs. $33 \sim 35$. The dimensions of each wind tunnels for round robin tests are shown in Table 8. Boundary layer thickness of the wind velocity profiles is about $130 \mathrm{~mm}$ in NMRI and about $30 \sim 50 \mathrm{~mm}$ in the other wind tunnels. The comparisons of the wind resistance coefficients measured in the three wind tunnels are shown in Figs. 36(a) 36(c). The measured data in the three wind tunnels are all non-dimensionalized with averaged wind velocities $U_{A 1}$ and $U_{A 2}$. The three data sets of the round robin tests have differences from the mean line of about $\pm 6 \%, \pm 3 \%$ and $\pm 3 \%$ in $C_{X}, C_{Y}$ and $C_{N}$ respectively.

\section{5 Influence of Differences in the Coefficients of Wind}

Resistances and Moment on Speed Reduction and Required

\section{Engine Output of a Ship}

The differences of $C_{X}, C_{Y}$ and $C_{N}$ in the round robin tests were reported above as $\pm 6 \%$, $\pm 3 \%$ and $\pm 3 \%$ when $U_{A 1}$ and $U_{A 2}$ are used for non-dimensionalization. As a next step, the influence of the differences, which affects to the accuracy of estimation of the speed reduction was examined by a program VESTA (Vessel Performance Evaluation Tool in Actual Seas) ${ }^{8)}$ under the condition of constant engine output. A result of examination using PCC, which is known as strongly affected by winds, is shown in Fig. 37. The influence of the differences in coefficients was estimated to be about \pm 0.02 knots of the speed reduction in the averaged sea condition (Wave and wind directions are averaged in all direction) of Beaufort Scale 6 (BF 6) and it corresponds to the error of estimation about $\pm 0.4 \%$ of required engine output.

It is found that the calculation method for the representative wind velocity using $U_{A 1}$ and $U_{A 2}$ has practically sufficient accuracy to evaluate the ship performance in actual seas, and the applicability of the arbitrary wind velocity profile at wind tunnel tests are also confirmed by the round robin tests.

\section{Conclusions}

We measured the wind resistance of several types of ship models with different boundary layer thickness distributions, and showed the effectiveness of the usage of the averaged wind velocity derived from integration of the squared values of wind velocity as a representative wind velocity. This calculation process can convert and align the wind resistance coefficients measured under different wind velocity profiles to the values as though those were measured under the same condition. As a result of the verification in this study, it is found that the wind resistance coefficients could be obtained with practically sufficient accuracy even with a simpler method of integration of the squared values of the wind velocity, even if there was a difference in the wind velocity profiles within the range of 30 to $130 \mathrm{~mm}$ in the boundary layer thickness.

In fact, the coefficient of variation of $C_{X}$ of Bulk Carrier decreases to 0.07 when using $U_{10 m}$ or $U_{A I}$ compared to 0.17 when using $U_{\text {ref. }}$ The same applies to wind tunnels in which the boundary layer distribution developed naturally on the wind tunnel floor without any turbulence stimulators, as in this study.

When we view the wind velocity profiles in wind tunnels, the flow distributions near model ships are close to $1 / 9$ power to $1 / 7$ power distribution in the cases of Case-A and Case-B which have the boundary layer thicknesses of about $130 \mathrm{~mm}$ and about 90 $\mathrm{mm}$, and Case-C has an almost uniform distribution with a boundary layer thickness of about $30 \mathrm{~mm}$.

All these things make it clear that the wind velocity profile during the wind resistance test in a wind tunnel does not necessarily to faithfully reproduce the power law distribution or including the advance speed of a ship which a ship will encounter at sea. It is considered that the wind velocity profile having a characteristic of a naturally developed boundary layer on a wind tunnel floor without any turbulence stimulators or a uniform flow can be employed for the wind resistance measurement.

\section{Acknowledgments}

This research was performed by the Project for Evaluation of Ship Performance in Actual Seas - Japan Maritime Cluster Collaborative Research - (OCTARVIA Project). The authors would like to express their gratitude for the support and suggestions.

The authors are also grateful to Dr. Toshifumi Fujiwara for providing valuable advices to determine the direction of this research and Mr. Tadashi Nimura for giving us appropriate instructions to perform measurements successfully in the wind tunnel.

\section{References}

1) Whitbread, R. E.: Model Simulation of Wind Effects on Structures, Proceedings of International Conference on Wind Effects on Buildings and Structures, pp. 284-302, 1963.

2) Blendermann, W.: Estimation of Wind Loads on Ships in Wind with a Strong Gradient, Proceedings of OMAE, Vol. 1-A, pp. 271-277, 1995.

3) Fujiwara, T., Ueno, M. and Nimura, T.: Estimation of Wind Forces and Moments acting on Ships [in Japanese], Journal of SNAJ, Vol. 183, pp. 77-90, 1998.

4) Nonaka, K., Nimura, T., Ueno, M., Fujiwara, T., Miyazaki, H. and Haraguchi, T.: Basic Study on External Forces and a Drifting Motion of a Ship [in Japanese], Report of Ship Research Institute, No. 5, Vol. 36, pp. 1-41, 1999.

5) Fujiwara, T., Ueno, M. and Ikeda, Y.: Cruising Performance of Ships with Large Superstructures in Heavy Sea -1st Report: Added Resistance Induced by Wind- [in Japanese], Journal of JASNAOE, Vol. 2, pp. 257-269, 2005.

6) Wagner, B.: Windkrafte an Uberwasserschiffen [in German], Schiff und Hafen, pp. 894-900, 1967.

7) Tsuji, T., Takaishi, Y., Kan, M. and Sato, T.: Model Test 
about Wind Forces Acting on the Ships [in Japanese], Report of Ship Research Institute, No. 5, Vol. 7, pp. 13-37, 1970.

8) Tsujimoto, M., Sogihara, N., Kuroda, M. and Sakurada, A.: Development of a Ship Performance Simulator in Actual Seas, Proceedings of the ASME 2015 34th International Conference on Ocean, Offshore and Arctic Engineering, Vol.11, 2015. 
Wind Velocity Profile and Representative Wind Velocity for Wind Resistance Measurement of Ship Models 9

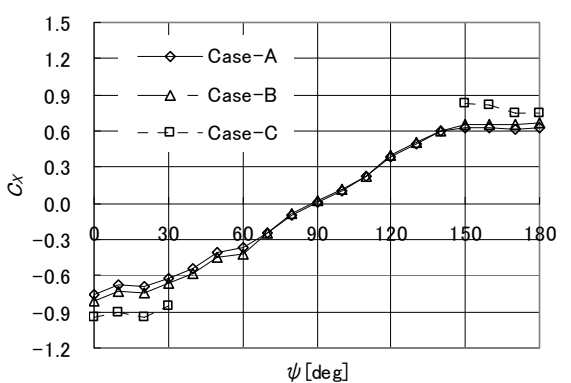

(a) using $U_{\text {ref }}$.

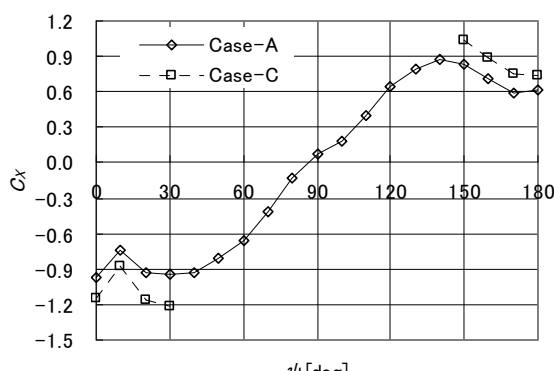

(a) using $U_{\text {ref. }}$.

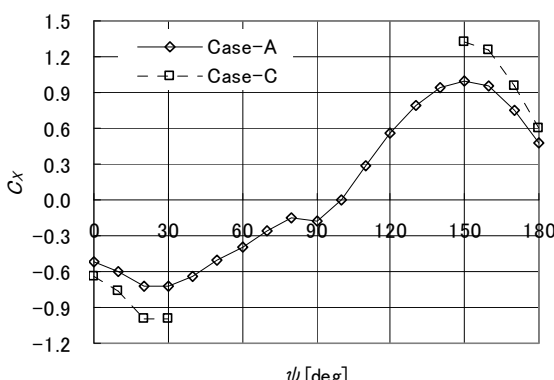

(a) using $U_{\text {ref }}$

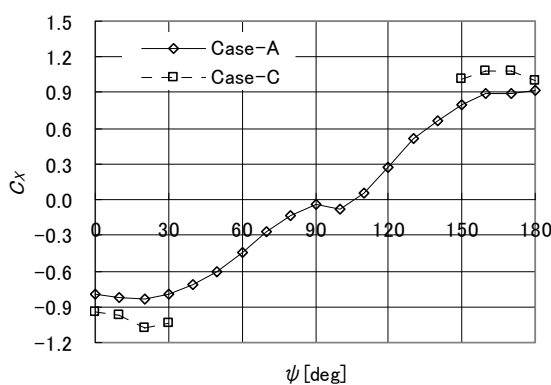

(a) using $U_{\text {ref. }}$.

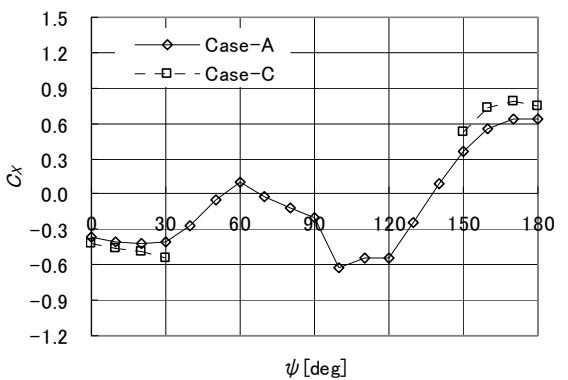

(a) using $U_{\text {ref }}$.

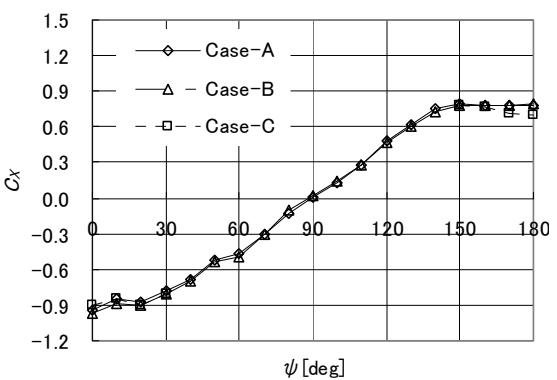

(b) using $U_{10 m}$.

Fig. $16 C_{X}$ of Bulk Carrier.

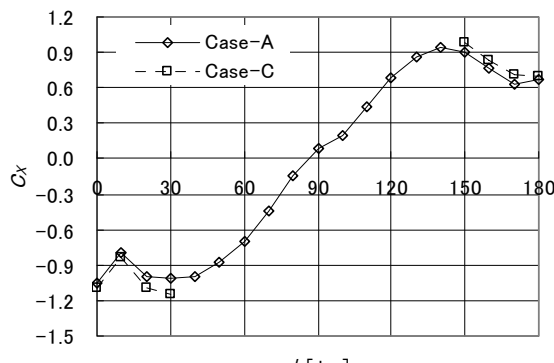

(b) using $U_{10 \mathrm{~m}}$.

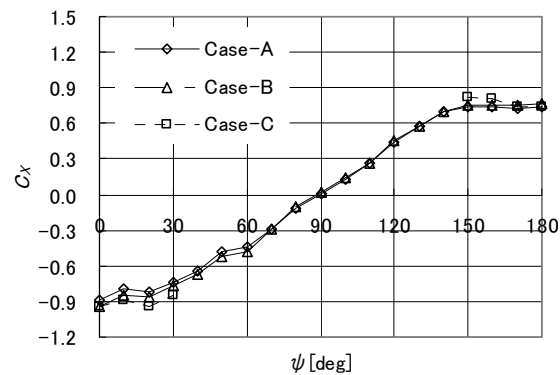

(c) using $U_{A 1}$.

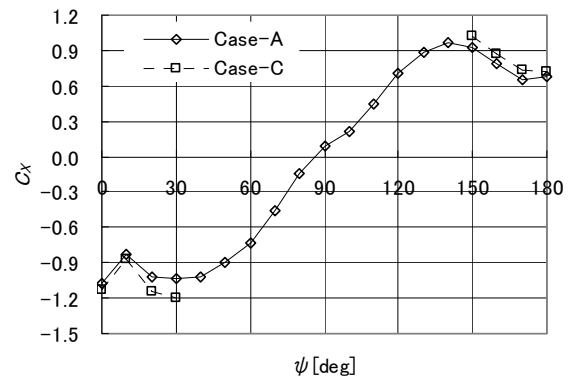

(c) using $U_{A 1}$.

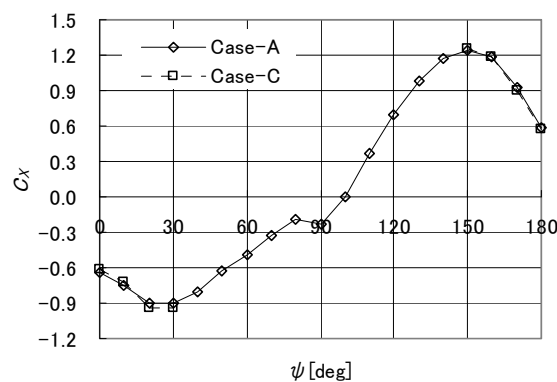

(b) using $U_{10 \mathrm{~m}}$.

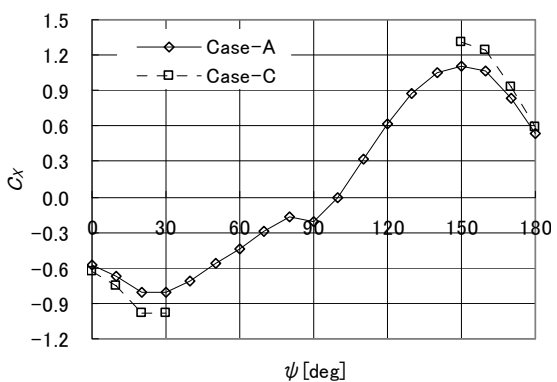

(c) using $U_{A I}$.

Fig. $18 C_{X}$ of Container Ship (Full Load Condition).

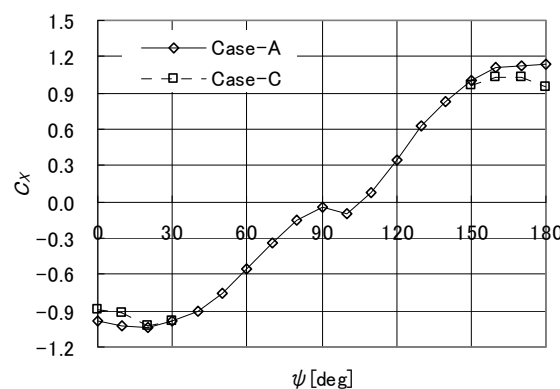

(b) using $U_{10 m}$.

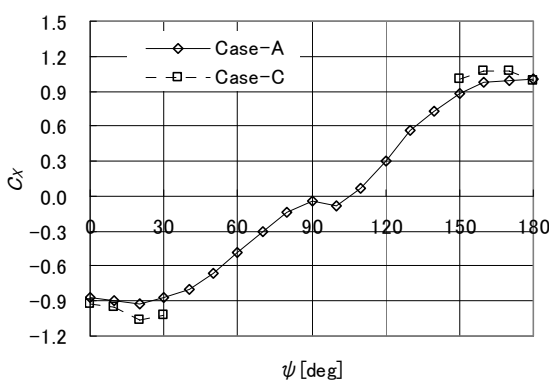

(c) using $U_{A I}$.

Fig. $19 C_{X}$ of Container Ship (Ballast Condition).

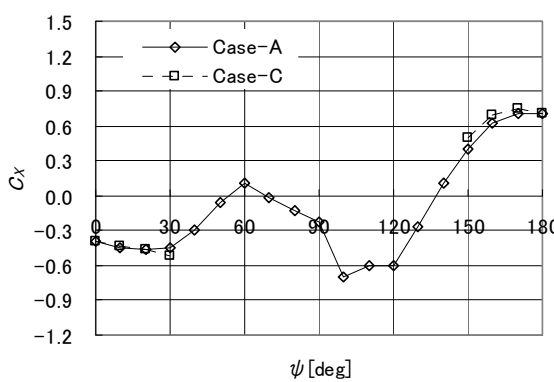

(b) using $U_{10 m}$.

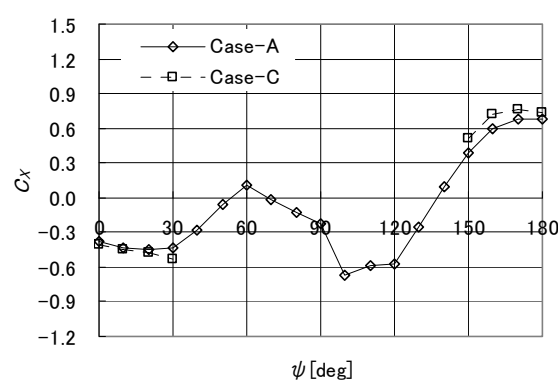

(c) using $U_{A 1}$.

Fig. $20 C_{X}$ of PCC. 


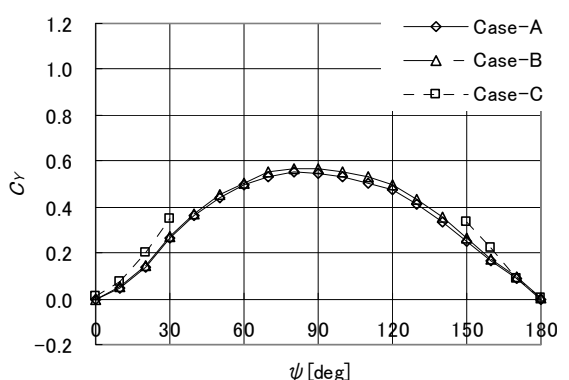

(a) using $U_{r e f}$.

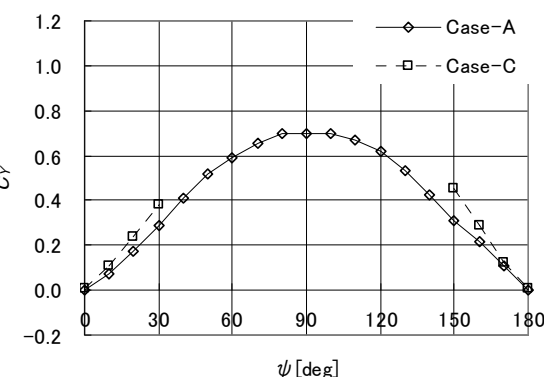

(a) using $U_{\text {ref. }}$.

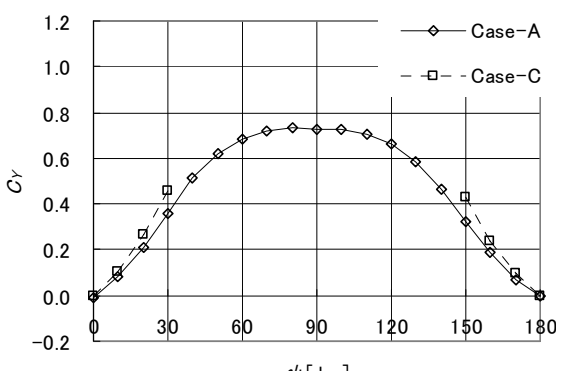

(a) using $U_{r e f}$.

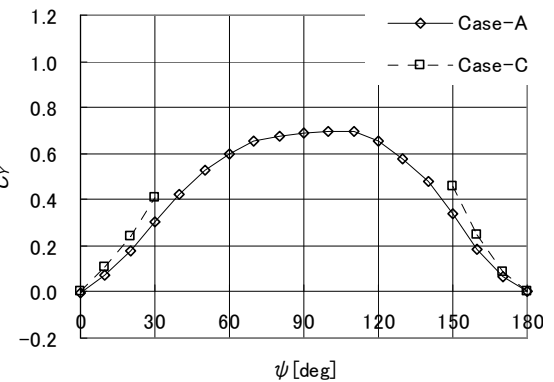

(a) using $U_{\text {ref. }}$.

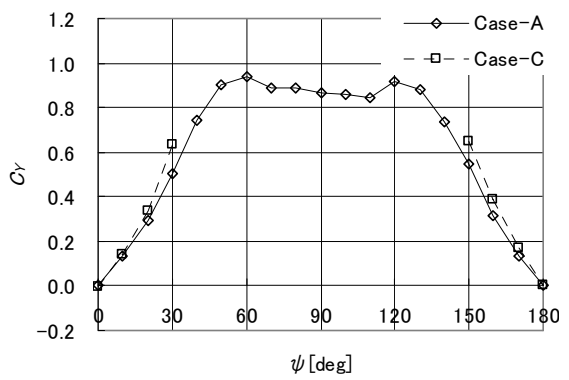

(a) using $U_{r e f}$.

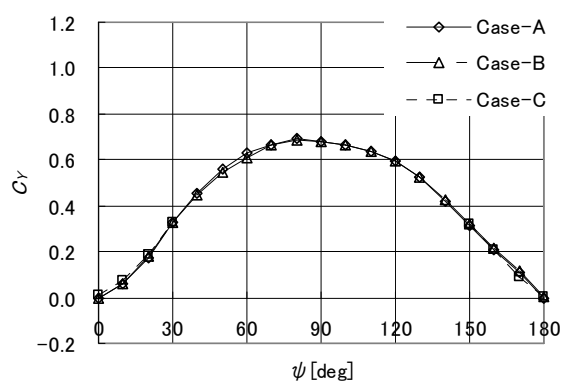

(b) using $U_{10 \mathrm{~m}}$.

Fig. $21 C_{Y}$ of Bulk Carrier.

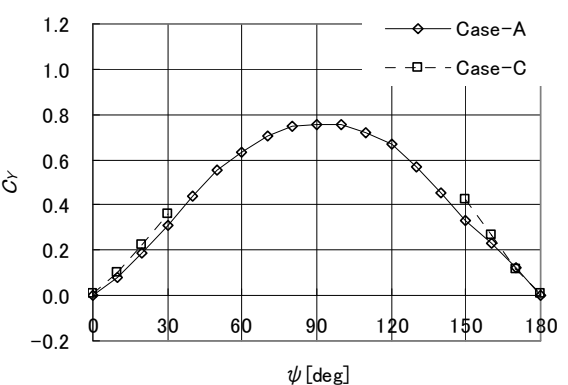

(b) using $U_{10 \mathrm{~m}}$.

Fig. $22 C_{Y}$ of Chemical Tanker.

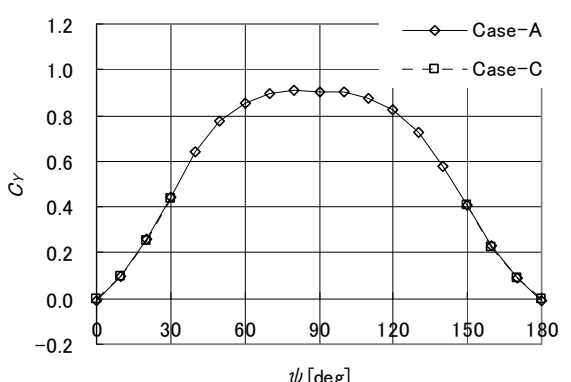

(b) using $U_{10 m}$.

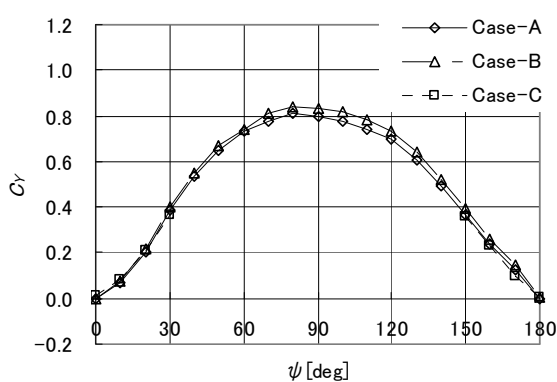

(c) using $U_{A 2}$.

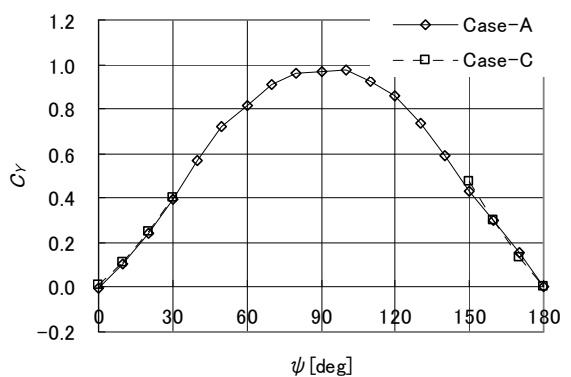

(c) using $U_{A 2}$.

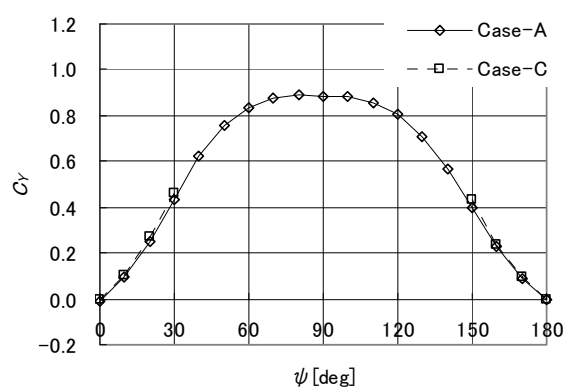

(c) using $U_{A 2}$.

Fig. $23 C_{Y}$ of Container Ship (Full Load Condition).

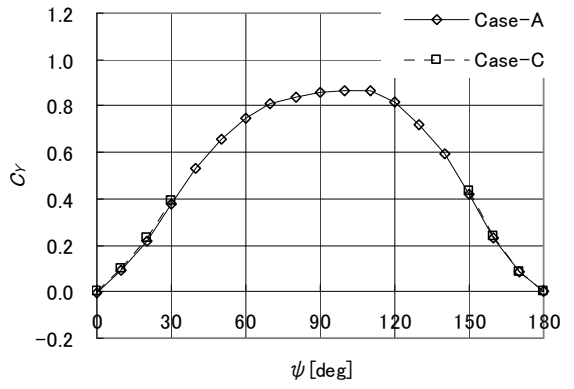

(b) using $U_{10 m}$.

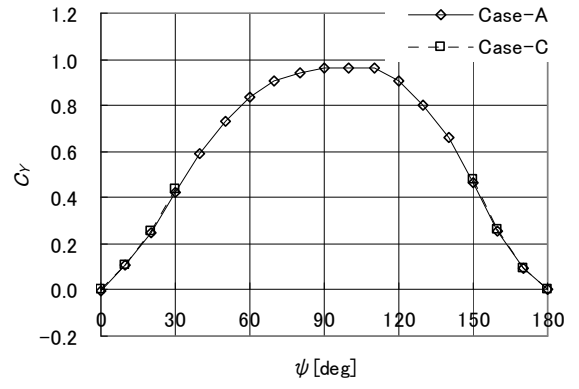

(c) using $U_{A 2}$.

Fig. $24 C_{Y}$ of Container Ship (Ballast Condition).

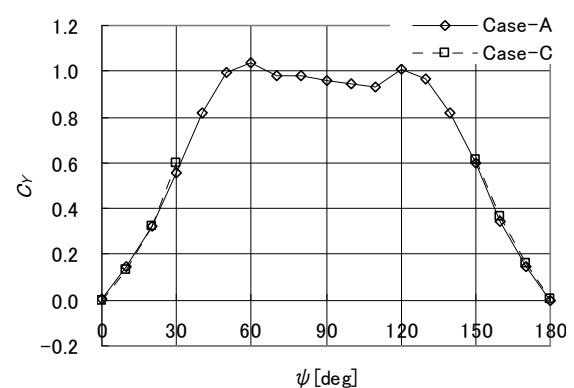

(b) using $U_{10 m}$.

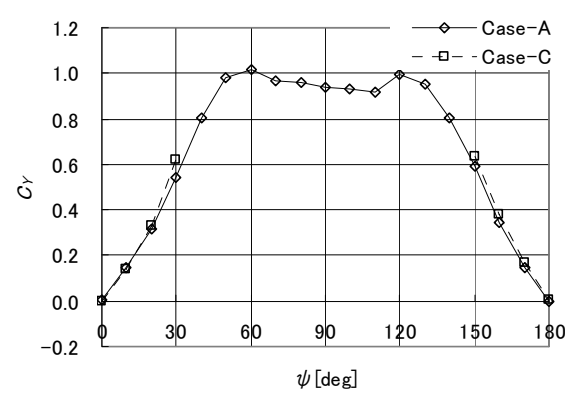

(c) using $U_{A 2}$.

Fig. $25 C_{Y}$ of PCC. 
Wind Velocity Profile and Representative Wind Velocity for Wind Resistance Measurement of Ship Models 11

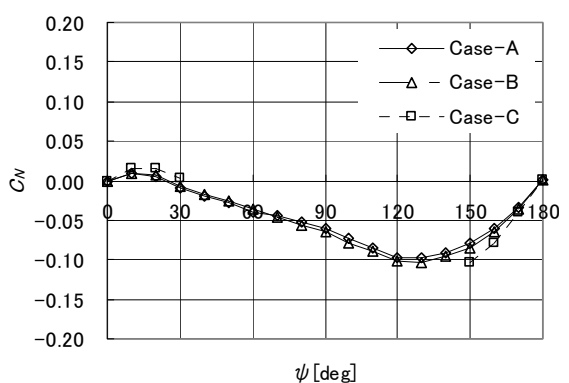

(a) using $U_{r e f}$.

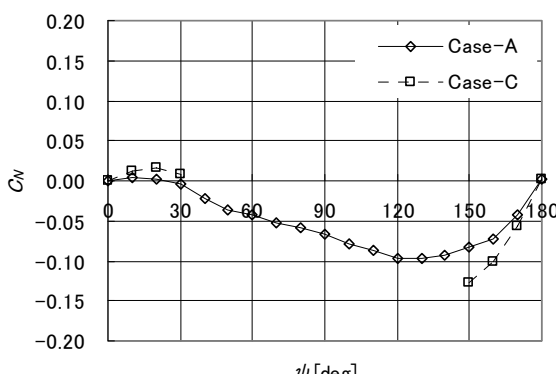

(a) using $U_{\text {ref. }}$.

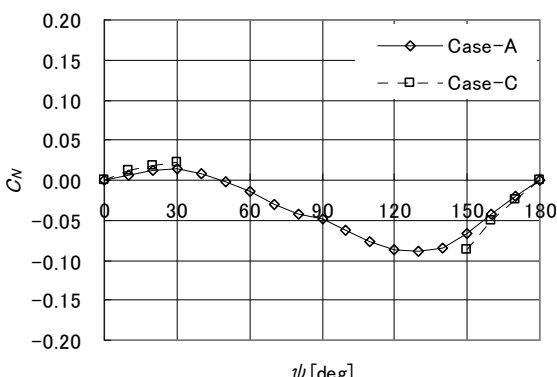

(a) using $U_{r e f}$.

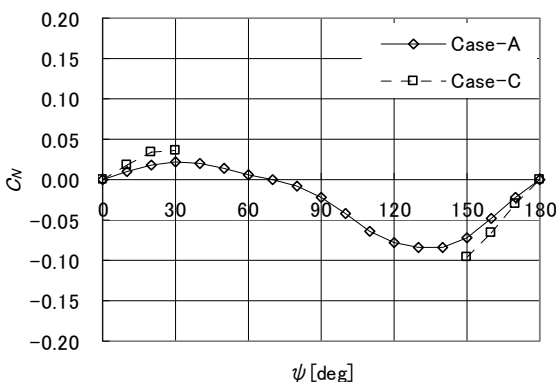

(a) using $U_{\text {ref. }}$.

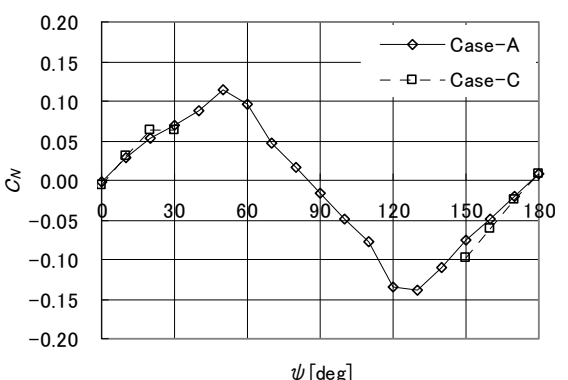

(a) using $U_{r e f}$

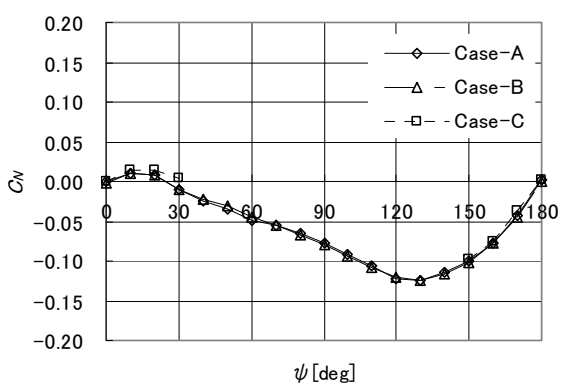

(b) using $U_{10 \mathrm{~m}}$.

Fig. $26 C_{N}$ of Bulk Carrier.

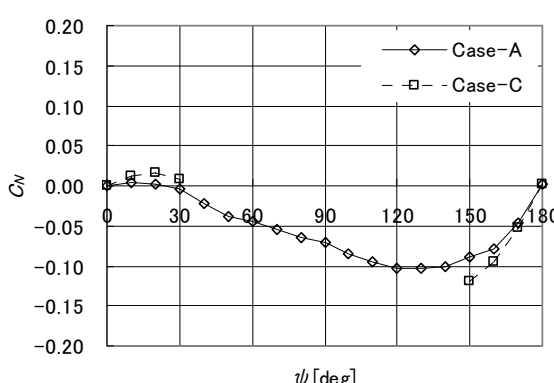

(b) using $U_{10 m}$.

Fig. $27 C_{N}$ of Chemical Tanker.

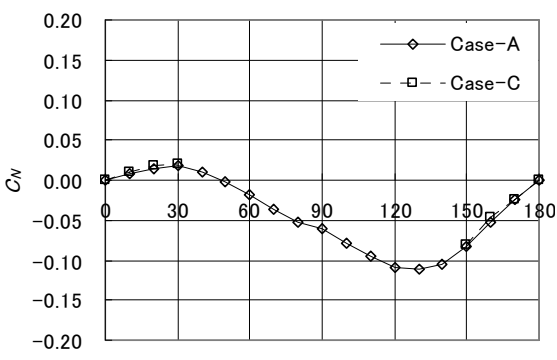

(b) using $U_{10 \mathrm{~m}}$.

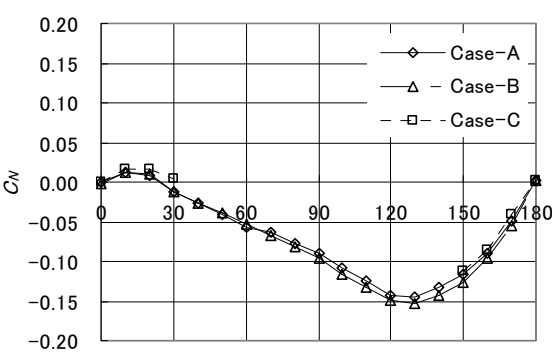

$\psi[\operatorname{deg}]$

(c) using $U_{A 2}$.

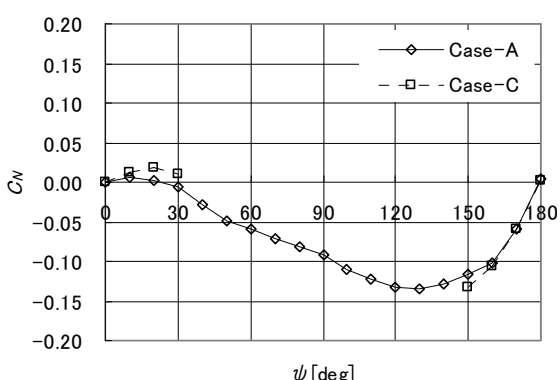

(c) using $U_{A 2}$.

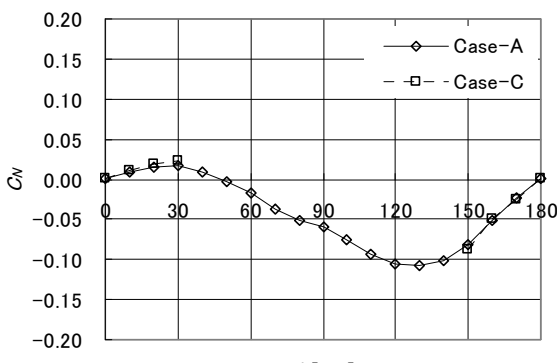

(c) using $U_{A 2}$.

Fig. $28 C_{N}$ of Container Ship (Full Load Condition).

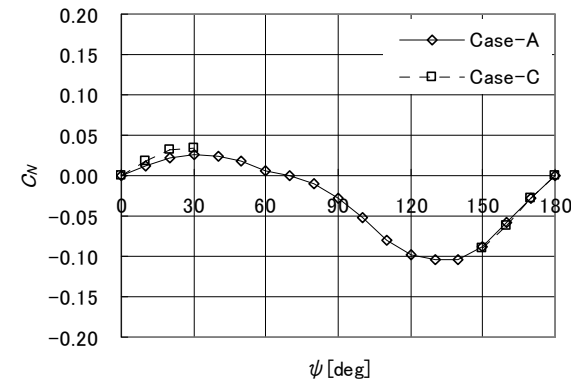

(b) using $U_{10 m}$.

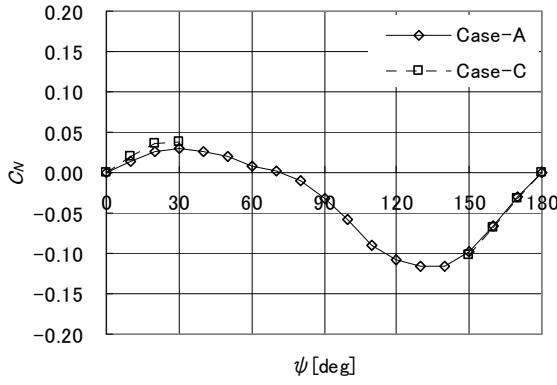

(c) using $U_{A 2}$.
Fig. $29 C_{N}$ of Container Ship (Ballast Condition).

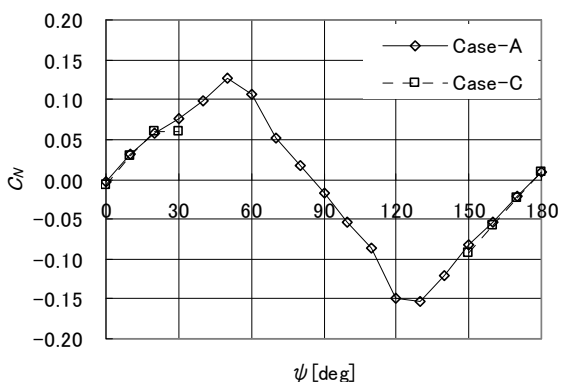

(b) using $U_{10 m}$.

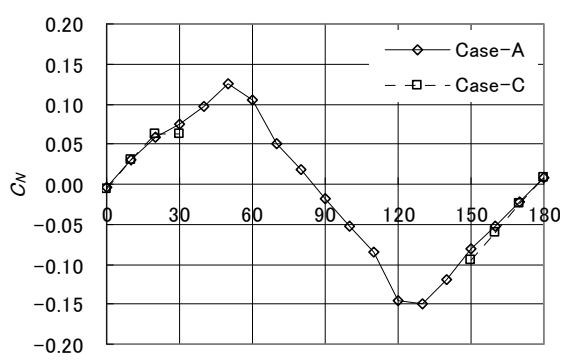

$\psi[\mathrm{deg}]$

(c) using $U_{A 2}$.
Fig. $30 C_{N}$ of PCC. 


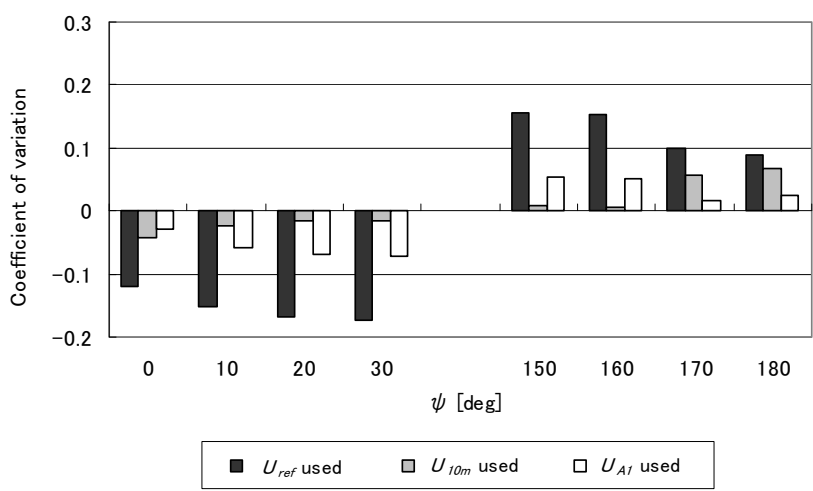

Fig. 31 Coefficient of variation of $C_{X}$ (Bulk Carrier).

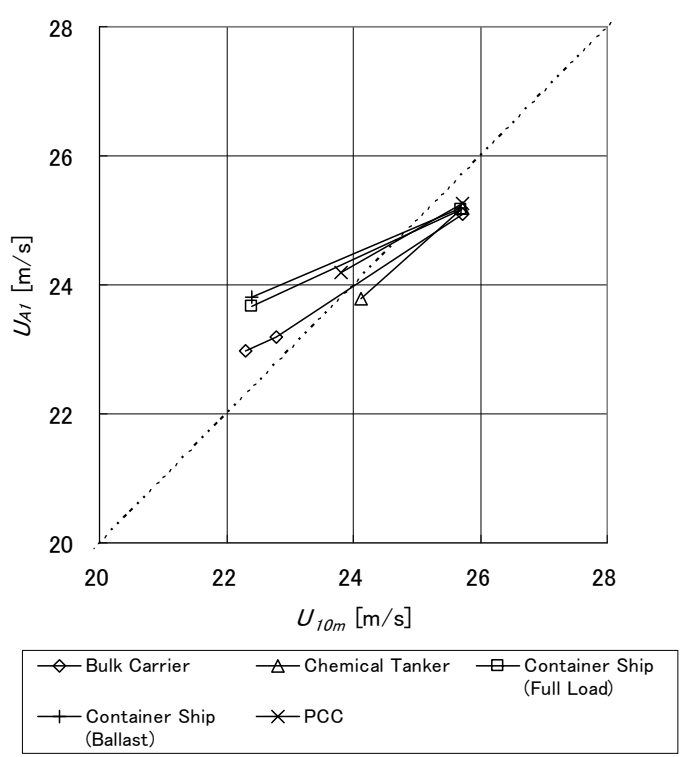

Fig. 32(a) Correlation diagram between $U_{A I}$ and $U_{10 m}$.

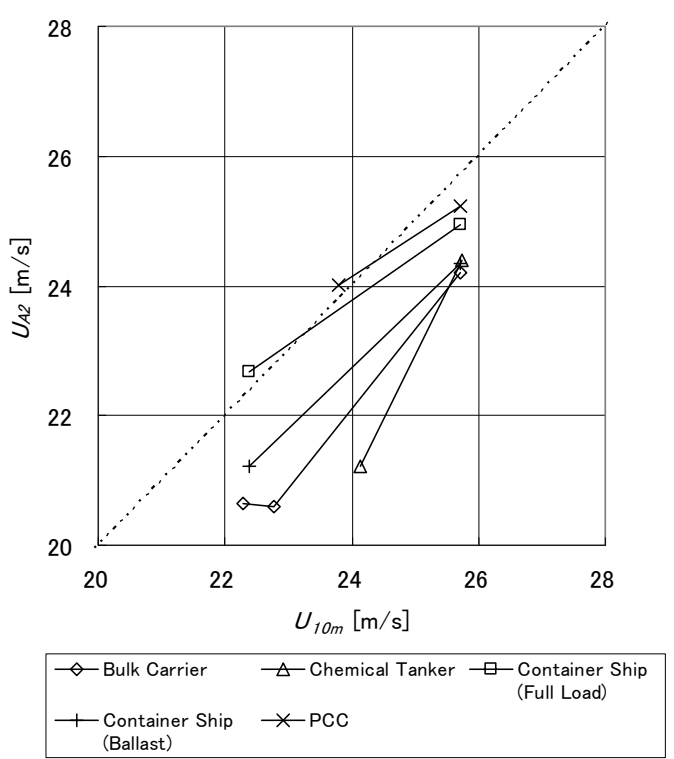

Fig. 32(b) Correlation diagram between $U_{A 2}$ and $U_{10 m}$.
Table 8 Dimensions of wind tunnels for round robin tests.

\begin{tabular}{|c|c|c|c|}
\hline & Test section & $\begin{array}{c}\text { Max. wind } \\
\text { velocity }\end{array}$ & $\begin{array}{c}\text { Thickness of } \\
\text { boundary layer }\end{array}$ \\
\hline $\begin{array}{c}\text { Tunnel-A } \\
\text { (NMRI) }\end{array}$ & $15 \times 3 \times 2 \mathrm{~m}$ & $30 \mathrm{~m} / \mathrm{s}$ & abt. $130 \mathrm{~mm}$ \\
\hline $\begin{array}{c}\text { The other } \\
\text { tunnels }\end{array}$ & $24 \times 6 \times 3 \mathrm{~m}$ & $15 \mathrm{~m} / \mathrm{s}$ & abt. $30 \mathrm{~mm}$ \\
\cline { 2 - 4 } & $30 \times 6 \times 5 \mathrm{~m}$ & $20 \mathrm{~m} / \mathrm{s}$ & abt. $50 \mathrm{~mm}$ \\
\hline
\end{tabular}

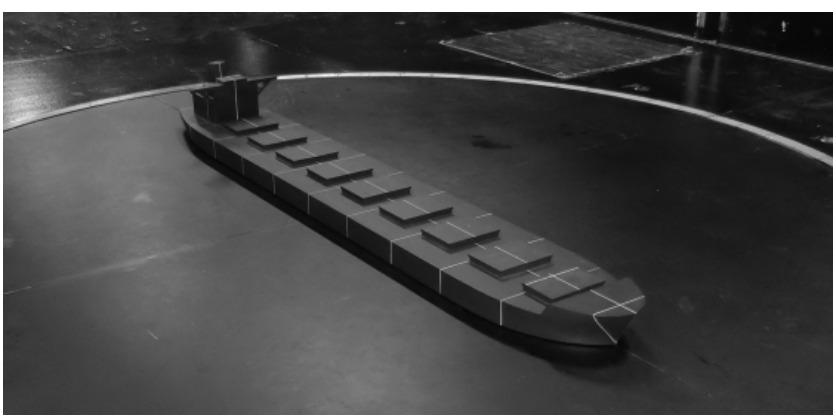

Fig. 33 Bulk Carrier model under the wind tunnel test (NMRI).

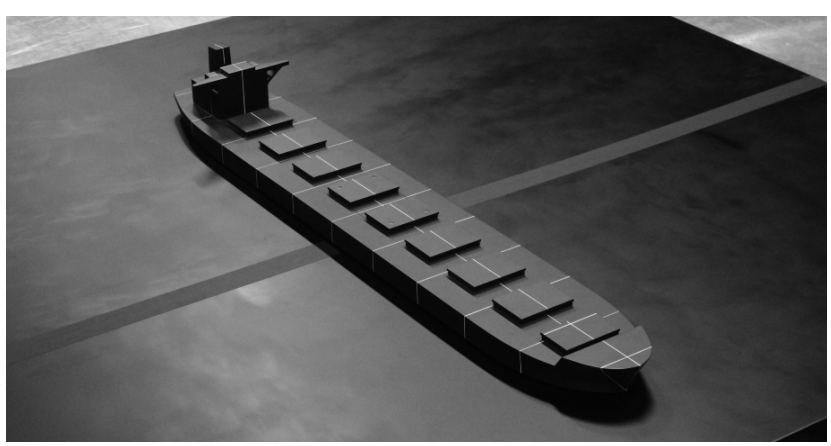

Fig. 34 Bulk Carrier model under the wind tunnel test (other than NMRI, 1 of 2 ).

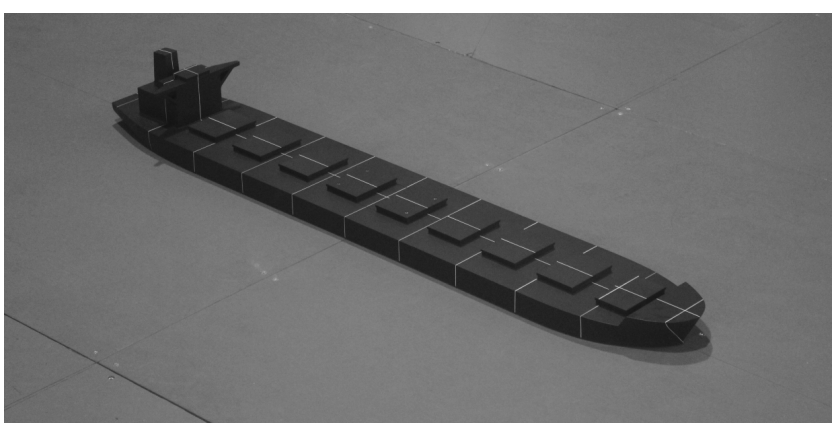

Fig. 35 Bulk Carrier model under the wind tunnel test (other than NMRI, 2 of 2). 


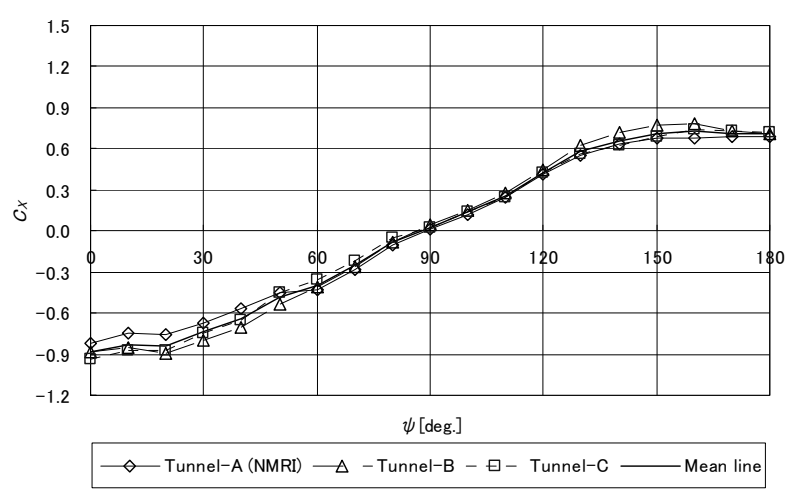

Fig. 36(a) Comparison of $C_{X}$ measured in three different wind tunnels with Bulk Carrier model (using $U_{A I}$ ).

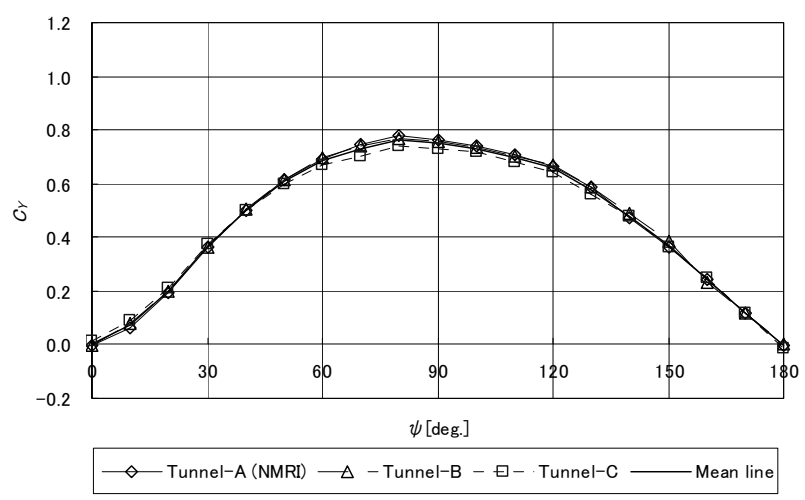

Fig. 36(b) Comparison of $C_{Y}$ measured in three different wind tunnels with Bulk Carrier model (using $U_{A 2}$ ).

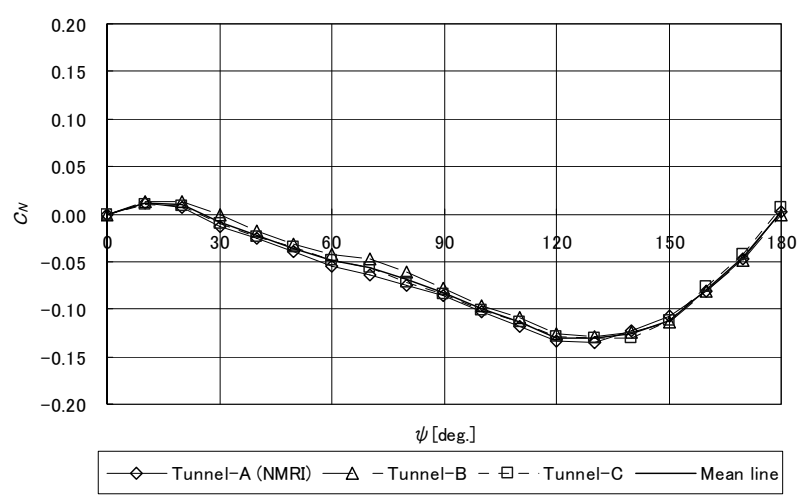

Fig. 36(c) Comparison of $C_{N}$ measured in three different wind tunnels with Bulk Carrier model (using $U_{A 2}$ ).

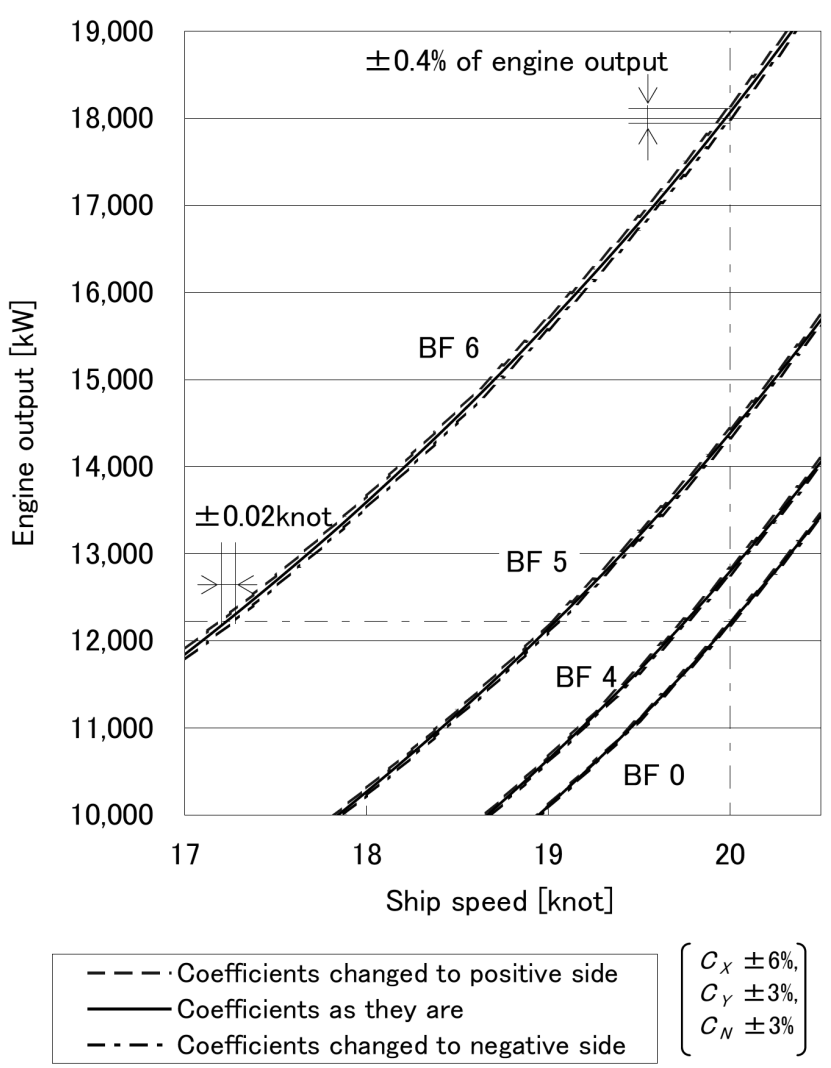

Fig. 37 Influence of the difference in wind resistance coefficients on power curves of PCC. 